\title{
The Effectiveness of Comprehensive Health Education Programming to Decrease Cardiovascular Health Disparities: The Case of HeartSmarts
}

\author{
Naa-Solo Tettey ${ }^{1}$ \\ ${ }^{1}$ Public Health Department, William Paterson University, Wayne, NJ, USA \\ Correspondence: Naa-Solo Tettey, Public Health Department, William Paterson University, Wayne, NJ, 300 \\ Pompton Road, University Hall, Suite 359, Wayne, NJ 07470, USA. Tel: 1-703-720-2604. E-mail: \\ tetteyn@wpunj.edu
}

Received: January 1, 2019 Accepted: February 15, 2019 Online Published: February 21, 2019

doi:10.5539/gjhs.v11n3p68 URL: https://doi.org/10.5539/gjhs.v11n3p68

\begin{abstract}
Introduction: Chronic illnesses, such as heart disease, affect African Americans at disproportionately higher rates due in part to low health literacy and a lack of comprehensive health education programs.

Purpose: The purpose of this research is to demonstrate the effectiveness of HeartSmarts, a culturally tailored, comprehensive cardiovascular health education program, in improving cardiovascular health literacy.

Methods: Peer health educators were trained to deliver an extensive curriculum focused on cardiovascular disease and its risk factors. Upon completion, they delivered this curriculum in their churches and communities. Pre- and post-assessments were administered for blood pressure, weight, waist circumference, and knowledge of cardiovascular disease.

Results: Fourteen predominantly African American churches in New York City participated, and 199 participants completed the program. Participants experienced decreases in blood pressure and weight, improved their health-related behaviors, and significantly increased their knowledge of cardiovascular health.

Conclusion: The HeartSmarts program demonstrates the effectiveness of using a comprehensive health education approach to help combat these issues. Programs that use strategies similar to HeartSmarts should be implemented for other health conditions to decrease health disparities.
\end{abstract}

Keywords: health disparities, health education, health literacy, heart disease, social justice

\section{Introduction}

Chronic disease is a major social justice issue. Preventable, non-communicable illnesses, such as heart disease, diabetes, and hypertension, affect African Americans at much higher rates than those of the general population and lead to greater morbidity and mortality within this group (Centers for Disease Control and Prevention [CDC], 2014a). Lack of access to nutritious food, safe spaces for exercise, quality healthcare, and chronic stress, coupled with low health literacy, have contributed to these disparities (CDC, 2014b). Due to the higher levels of chronic disease in African Americans, the assumption is often made that they have a basic understanding of these health conditions. Although studies have shown that African Americans have a desire to prevent chronic illnesses (Viswanathan \& Lambert, 2005) and acquire some knowledge of the consequences of these diagnoses (Longtin, Sax, Leape, Sheridan, Donaldson, \& Pittet, 2010), there is still a limited understanding of the actual conditions, causes, prevention strategies, and treatment. These gaps in understanding can have detrimental effects related to health-seeking and self-management behaviors, positive lifestyle changes, disease management, medication adherence, and overall perception of health issues (Dickinson \& Plauschinat, 2008; Mann, Ponieman, Leventhal, \& Halm, 2009).

Although brief health promotion interventions, such as health fairs and health-focused workshops, which can serve to encourage participants to seek more information or care, have continued to increase in high-risk communities, there is a vital need for more comprehensive and substantive health education regarding chronic disease (Bergman, Reeve, Moser, Scholl, \& Klein, 2011). The purpose of this paper is to demonstrate the effectiveness of using a comprehensive health education strategy, such as the HeartSmarts program, to increase cardiovascular health 
literacy in high-risk communities.

\subsection{Health Literacy and Social Justice}

Health literacy is defined as the degree to which a person is able to obtain, process, and understand basic health-related information and health services and to use these resources to make informed health decisions (Ratzan \& Parker, 2000). There is a relationship between health literacy and health outcomes, with decreased health literacy being directly linked to poor health outcomes (Berkman et al., 2011). Improved health literacy is not just an individual's ability to understand health information but also includes access to this information either through healthcare providers or within the community (Coleman et al., 2011). Limited health literacy is a central component of health disparities that requires more exploration. Further, the fact that some communities may have access to health information while other communities that are primarily poor and minority do not is a social justice issue that creates health inequities (Volandes \& Paasche-Orlow, 2007). Improvements in health literacy are positively correlated with decreased risk behaviors for chronic disease (Taggart et al., 2012) and decreased rates of hospitalization (Cho, Arozullah, Crittenden, \& Lee, 2008).

\subsection{HeartSmarts Program}

Although the information presented in this paper could pertain to chronic illness in general, the focus will be on cardiovascular disease (CVD), specifically, heart disease. Heart disease is the leading cause of death globally and the number one killer of all Americans (Hoyert \& Xu, 2012). Compared to the general population, African Americans have higher rates of CVD risk factors and experience greater morbidity and mortality as a result of CVD (Martins, Tareen, Ogedegbe, Pan, \& Norris, 2008). Further, African American men and women have a higher incidence of fatal coronary heart disease compared to Caucasians (Safford et al., 2012). Due to higher rates of hypertension, diabetes, physical inactivity, and obesity, African Americans also have higher incidences of heart attack and stroke than do Caucasians and higher death rates for strokes than do all other ethnic groups (Go et al., 2013). Changes in behaviors related to lifestyle, guided by health education and health promotion programs, have been shown to prevent heart disease (Artinian et al., 2010). Limited access to effective, culturally tailored cardiovascular health education programs, however, has served as a barrier to disease prevention for African American communities that are already lacking in quality healthcare services and resources (Copeland, 2005).

Faith-based organizations establish a social safety net in many African American communities and provide social services, education, social support, and health programs (Johnson, 2002). Faith-based organizations have sought to address health disparities and the social determinants of health by providing health-related interventions for high-risk communities (Harmon, Blake, Armstead, \& Hebert, 2013). Many of these interventions, however, are faith-placed rather than faith-based and are often offered by organizations that would like to obtain data rather than those committed to increasing health knowledge and improving health behavior. This distinction is important because it highlights one of the reasons that lasting behavior change is difficult to achieve.

It is often assumed that, when people are diagnosed with a health condition, they understand what this diagnosis means, the best methods for managing the condition, and the effect of their medication, but this is not always the case (Phillips, Rogers, \& Aiken-Morgan, 2017). Further, although prevention efforts may exist, effective and sustained prevention cannot truly occur if those who are most affected by a health issue do not know exactly what they are preventing or have low health literacy. The purpose of the HeartSmarts program is to increase knowledge of CVD and associated health literacy in high-risk communities.

HeartSmarts is a faith-based cardiovascular health education program that trains lay health educators to teach others about heart disease and its prevention (Tettey, Duran, Andersen, Washington, \& Boutin-Foster, 2016). The program was created in 2011 as a partnership between a large teaching hospital, faith-based organizations, and community members. One aim of the program is to empower participants by increasing their understanding of CVD and the related risk factors. The long-term goal is to create effective and sustainable partnerships between communities and academic institutions that can be used to develop ongoing comprehensive health education programs to reduce the health disparities related to CVD (Tettey, Duran, Andersen et al., 2016).

The research team that developed the HeartSmarts program developed an intervention for which health education is at the forefront. Program developers wanted participants to leave the program more knowledgeable and empowered to advocate for themselves regarding their health and to make informed health decisions. Therefore, the curriculum is extensive and detailed; it is delivered over a 12-week period, 3 hours each week, and covers the major risk factors of heart disease. As a result of the partnership with a teaching hospital, participants have access to leading experts in cardiovascular health, who supplement the information provided in the text. The curriculum is also culturally relevant and was developed using a community participatory approach; it includes both 
cardiovascular health and disease information as well as Biblical texts that complement the health messages. Construction of the HeartSmarts manual and development of the program is described elsewhere (Tettey, Duran, Andersen et al., 2016; Tettey, Duran, Andersen, \& Boutin-Foster, 2017). Due to the comprehensive nature of the program, participants are eligible to receive continuing education credits from various credentialing organizations, including the National Commission for Health Education Credentialing, Inc.

\section{Methods}

Upon completion of the HeartSmarts training, ambassadors returned to their churches and community organizations to deliver the 12-week program. Ambassadors adhered strictly to the curriculum content and procedures learned during their training. To ensure program fidelity, research assistants conducted site visits. A total of 221 individuals from the 14 churches participated in the program, of whom $80 \%$ were female, with an overall age range of 18 to 80 years. Of the 221 individuals who initially started the program, 199 participants (90\%) completed the classes. Prior to enrolling in the class, these participants had been diagnosed with health conditions such as pre-hypertension, hypertension, overweight, obesity, diabetes, heart disease, stroke, and heart attack. Many had CVD risk factors, such as a waist circumference above $35 \mathrm{in}$. for women or above $40 \mathrm{in}$. for men, minimal fruit and vegetable intake, lack of consistent exercise, chronic stress and unhealthy stress management behaviors, inadequate sleep, and insufficient water intake. To determine the effectiveness of this curriculum, ambassadors were trained to collect pre- and post-data for blood pressure, waist circumference, height, and weight. A CVD knowledge assessment (Appendix A) also was administered during Weeks 1 and 12 of the program (Tettey, Duran, Andersen et al., 2016).

Pre- and post-means for total participant data were calculated for systolic blood pressure (BP), diastolic BP, height, weight, and body mass index (BMI). Individual participants' pre- and post-variances also were analyzed for these measurements. The cardiovascular disease knowledge assessment was based on 20 open-ended questions, and preand post-means for total number of correct items were calculated following McNemar tests for individual items (Tettey, Duran, Andersen et al., 2016).

\section{Results}

A significant outcome of this study was the large improvement in CVD health knowledge assessment scores. These questions were open ended and concerned CVD terminology and risk factors (Appendix A). The pre-program CVD health knowledge assessment score averaged 5.6/20, while, the post-program average score was $18.34 / 20(p<0.001)$, an average improvement of 12.74. The post-program assessments indicated that there were significant improvements in total participant averages for systolic BP, diastolic BP, weight, and BMI over the 12 -week period. The average reduction was $4.48 \mathrm{mmHg}$ for systolic $\mathrm{BP}(p<0.001), 3.83 \mathrm{mmHg}$ for diastolic $\mathrm{BP}(p$ $<0.001), 3 \mathrm{lbs}$. for weight $(p=0.001)$, and 0.46 for BMI $(p=0.001)$. There also were reductions in waist circumference and depression, but these were not found to be statistically significant. Table 1 provides a more detailed overview of participant results. Specifically, $57.9 \%$ of participants had improvement in systolic BP and $56.3 \%$ in diastolic BP. Further, $64.5 \%$ lost weight, and $62.8 \%$ decreased their waist circumference. Finally, $77.39 \%$ of participants experienced improved sleep (Tettey, Duran, Andersen et al., 2016).

Table 1. Pre- and Post-program Means for Noted Markers $(\mathrm{N}=197)$

\begin{tabular}{lccc}
\hline Marker & Pre-program & Post-program & $p$-value \\
\hline Systolic BP (mmHg) & 135.39 & 130.91 & $<0.001$ \\
Diastolic BP (mmHg) & 83.14 & 79.31 & $<0.001$ \\
Weight (lbs.) & 180.53 & 177.53 & 0.001 \\
BMI (lb./in. ${ }^{2}$ x 703) & 30.41 & 29.95 & 0.001 \\
Waist circumference (in.) & 37.99 & 37.38 & 0.254 \\
Depression (out of 2) & 0.26 & 0.22 & 0.574 \\
CVD Health Assessment (number correct) & 5.60 & 18.34 & $<0.001$ \\
\hline
\end{tabular}

Note. $\mathrm{BP}=$ blood pressure, $\mathrm{BMI}=$ body mass index. 


\section{Discussion}

When communities are suffering from preventable health issues and do not have access to the information needed to adequately prevent and manage these conditions, this can be considered health inequity and social injustice (Hill, 2004; Hasnain-Wynia \& Wolf, 2010). Because the causes of heart disease are multifactorial, it will not be possible to reduce the incidence and prevalence of this condition until people gain a better understanding of the etiology, risk factors, treatment, and methods for prevention. A more comprehensive understanding is needed if there is to be substantial and sustainable change (Bergmen, Reeve, Moser, Scholl, \& Klein, 2011). The HeartSmarts program addresses this need. Although faith-based organizations offer many health education and promotion programs that provide an overview or introduction to a health issue, HeartSmarts educates participants in a way that can lead to more substantial changes. Many of the HeartSmarts participants presented with the health issues and unhealthy lifestyle behaviors that can lead to heart disease. However, these participants did not have a basic understanding of their diagnosis or steps that could be taken for prevention or management. For example, some participants who were diagnosed with hypertension could not explain what hypertension is or how to prevent it in their pre-assessment. The same was true for many participants diagnosed with diabetes and heart disease. This low level of cardiovascular health literacy is detrimental to their overall health.

Participants shared through their feedback, the need to continue the HeartSmarts classes and develop similar programs for other health issues, as well as the desire to share what they have learned with other community members. Contrary to the belief that higher-level health information may be too overwhelming for certain groups, the HeartSmarts program had a $90 \%$ attendance rate. The participants had varying levels of education and benefitted from the incorporation of principles of health literacy and user-friendly program format.

From a social justice, health equity perspective, it is not acceptable that people are suffering from various adverse health conditions and do not have the resources, including health education, that they need to make positive health changes (Hill, 2004). Providing written information such as pamphlets and brochures and short health interventions like health fairs can be helpful initially, but lasting change will only be achieved once communities are given the comprehensive knowledge and skills needed to effectively advocate for their health, ensure that their communities promote health, and navigate the healthcare system. In addition, the way health information is taught in schools should be reexamined and more in-depth health education programs should be offered starting at younger ages.

It should be noted that this study of the HeartSmarts program has certain limitations. Due to the lack of substantial participation from men and individuals under the age of 40 , generalization of the study results is limited. The effectiveness of the intervention, however, highlights the need to recruit more men and younger participants and to develop programs that are specifically created for these groups. Although the Cardiovascular Disease Knowledge Assessment focused on cardiovascular risk factors, it is not a validated tool. Therefore, future studies should incorporate a measure for cardiovascular health knowledge that has been validated. Another limitation of this study was the focus on faith-based organizations. Future studies could consider the impact of such programs in secular community settings.

\section{Conclusion}

Education has been identified as a social determinant of health that can positively impact life outcomes. However, when it comes to health education, there is an unspoken belief that the general public, people without degrees or training in the medical field, should only be given certain amounts or types of information. It is evident that this approach is not working. For people to make changes, they need to understand why they are making these changes and how these changes will directly impact their personal health. Furthermore, there must be a shift towards empowerment where individuals stop relying solely on health professionals to explain health conditions. Increased understanding of health information can lead to greater commitment to prevention efforts and disease management protocol. Therefore, it is time to create more comprehensive, rigorous health education programming that equips participants to make lifelong changes and leads to a reduction in health disparities.

\section{Competing Interests Statements}

The author declares that there are no competing or potential conflicts of interest.

\section{References}

Artinian, N. T., Fletcher, G. F., Mozaffarian, D., Kris-Etherton, P., Van Horn, L., Lichtenstein, A. H., ... \& Meininger, J. C. (2010). Interventions to promote physical activity and dietary lifestyle changes for cardiovascular risk factor reduction in adults: a scientific statement from the American Heart Association. Circulation, 122(4), 406-441. https://doi.org/10.1161/CIR.0b013e3181e8edf1 
Bergman, H. E., Reeve, B. B., Moser, R. P., Scholl, S., \& Klein, W. M. P. (2011). Development of a comprehensive heart disease knowledge questionnaire. American Journal of Health Education, 42(2), 74-87. https://doi.org/10.1080/19325037.2011.10599175

Centers for Disease Control and Prevention. (2014a). Black or African-American populations. Retrieved from http://www.cdc.gov/minorityhealth/populations/remp/black.html

Centers for Disease Control and Prevention. (2014b). Health of Black or African-American non-Hispanic populations. Retrieved from http://www.cdc.gov/nchs/fastats/black-health.htm

Cho, Y. I., Arozullah, A. M., Crittenden, K. S., \& Lee, S. Y. D. (2008). Effects of health literacy on health status and health service utilization amongst the elderly. Social Science and Medicine, 66, 1809-1816. https://doi.org/10.1016/j.socscimed.2008.01.003

Coleman, C., Kurtz-Rossi, S., McKinney, J., Pleasant, A., Rootman, I., \& Shohet, L. (2011). The Calgary Charter on Health Literacy: Rationale and core principles for the development of health literacy curricula. Retrieved from http://www.centreforliteracy.qc.ca/sites/default/files/CFL_Calgary_Charter_2011.pdf

Copeland, V. C. (2005). African Americans: disparities in health care access and utilization. Health \& Social Work, 30(3), 265-270. http://dx.doi.org/10.1093/hsw/30.3.265

Dickson, M., \& Plauschinat, C. (2008). Racial differences in medication compliance and healthcare utilization among hypertensive Medicaid recipients: Fixed-dose vs. free-combination treatment. Ethnicity \& Disease, 18(8), 204-209.

Go, A. S., Mozaffarian, D., Roger, V. L., Benjamin, E. J., Berry, J. D., Borden, W. B., . . Turner, M. B. (2013). Heart disease and stroke statistics-2013 update: A report from the American Heart Association. Circulation, 127, e6-e245. https://doi.org/10.1161/CIR.0b013e31828124ad

Harmon, B. E., Blake, C. E., Armstead, C. A., \& Hebert, J. R. (2013). Intersection of identities, food, role, and the African-American pastor. Appetite, 67, 44-52. Retrieved from https://dx.doi.org/10.1016/j.appet.2013.03.007

Hasnain-Wynia, R., \& Wolf, M. S. (2010). Promoting health care equity: is health literacy a missing link? Health Services Research, 45(4):897-903. https://doi: 10.1111/j.1475-6773.2010.01134.x

Hill, L. H. (2004). Health literacy is a social justice issue that affects us all. Adult Learning, 15(1-2), 4-6. https://doi.org/10.1177/104515950401500101

Hoyert, D. L., \& Xu, J. Q. (2012). Deaths: Preliminary data for 2011. National Vital Statistics Reports, 61(6). Retrieved from http://www.cdc.gov/nchs/data/nvsr/nvsr61/nvsr61_06.pdf

Johnson, B. R. (2002). Objective hope: assessing the effectiveness of faith-based organizations: a review of the literature. New York, NY: Manhattan Institute Publications. Retrieved from http://www.manhattan-institute.org/pdf/crrucs_objective_hope.pdf

Longtin, Y., Sax, H., Leape, L. L., Sheridan, S. E., Donaldson, L., \& Pittet, D. (2010). Patient participation: Current knowledge and applicability to patient safety. Mayo Clinic Proceedings, 85(1), 53-62. http://doi.org/10.4065/mcp.2009.0248

Mann, D., Ponieman, D., Leventhal, H., \& Halm, E. (2009). Misconceptions about diabetes and its management among low-income minorities with diabetes. Diabetes Care, 32(4), 591-593. https://doi.org//10.2337/dc08-1837

Martins, D., Tareen, N., Ogedegbe, G., Pan, D., \& Norris, K. (2008). The relative risk of cardiovascular death among racial and ethnic minorities with metabolic syndrome: Data from the NHANES-II mortality follow-up. Journal of the National Medical Association, 100, 565-571. https://doi.org/10.1016/S0027-9684(15)31304-3

Phillips, K. L., Rogers, C. R., \& Aiken-Morgan, A. T. (2017). Perceptions of chronic disease among older African Americans: A qualitative analysis. Journal of Health Disparities Research and Practice, 10(4), 52-60.

Ratzan, S. C., \& Parker, R. M. (2000). Introduction: Health literacy. In C. Selden, M. Zorn, S. C. Ratzan, \& R. M. Parker (Eds.), Current bibliographies in medicine (No. 2000-1). Bethesda, MD: National Library of Medicine. Retrieved from http://www.nlm.nih.gov/archive//20061214/pubs/cbm/hliteracy.html

Safford, M. M., Brown, T. M., Muntner, P. M., Durant, R. W., Glasser, S., Halanych, J. H., . . Howard, G. (2012). Association of race and sex with risk of incident acute coronary heart disease events. Journal of the American Medical Association, 308(17), 1768-1774. https://doi:10.1001/jama.2012.14306

Taggart, J., Williams, A., Dennis, S., Newall, A., Shortus, T., Zwar N., . . Harris, M. F. (2012). A systematic 
review of interventions in primary care to improve health literacy for chronic disease behavioral risk factors. BMC Family Practice, 13, 49-60. https://doi.org/10.1186/1471-2296-13-49

Tettey, N., Duran, P. A., Andersen, H. S., Washington, N., \& Boutin-Foster, C. (2016). "It's like backing up science with scripture": Perceptions of HeartSmarts, a faith-based cardiovascular health education program. Journal of Religion and Health, 55(3), 1078-1088. https://doi.org/10.1007/s10943-016-0196-9

Tettey, N., Duran, P. A., Andersen, H. S., \& Boutin-Foster, C. (2017). Evaluation of HeartSmarts, a faith-based cardiovascular health education program. Journal of Religion and Health, 56(1), 320-328. https://doi.org/10.1007/s10943-016-0309-5

Viswanathan, H., \& Lambert, B. (2005). An inquiry into medication meanings, illness, medication use, and the transformative potential of chronic illness among African Americans with hypertension. Research in Social and Administrative Pharmacy, 1(1), 21-39. https:// doi.org/10.1016/j.sapharm.2004.12.007

Volandes, A. E., \& Paasche-Orlow, M. K. (2007). Health literacy, health inequality and a just healthcare system. The American Journal of Bioethics, 7, 5-10. https://doi.org/10.1080/15265160701638520

\section{Appendix A: Cardiovascular Disease Knowledge Assessment}

1a. What is cholesterol?

$1 \mathrm{~b}$. What is the number for healthy cholesterol?

2a. What is HDL cholesterol?

$2 b$. What is the desired number for HDL cholesterol?

3a. What is LDL cholesterol?

$3 b$. What is the desired number for LDL cholesterol?

4a. What is blood pressure?

$4 \mathrm{~b}$. What is high blood pressure?

5. What is the desired number for blood pressure?

6a. What are triglycerides?

$6 \mathrm{~b}$. What is the desired number for triglycerides?

7. What is diabetes?

8. What is the desired number for blood glucose (sugar)?

9. How can you improve any of these numbers if they are too high?

10. How are these numbers related to heart disease?

11. What is heart disease?

12. What are the risk factors for heart disease? 
13. What are some actions that a person can take to prevent heart disease?

14. What are you currently doing for exercise? (Activity, how long, how many days a week?)

15. What is your current diet? (What kinds of foods do you usually eat?)

Additional Sleep Items:

How many hours of sleep are you getting each night?

Did your sleep increase or improve as a result of taking the HeartSmarts Class?

\section{Copyrights}

Copyright for this article is retained by the author(s), with first publication rights granted to the journal.

This is an open-access article distributed under the terms and conditions of the Creative Commons Attribution license (http://creativecommons.org/licenses/by/4.0/). 